\title{
Hematological Malignancies in Systemic Lupus Erythematosus: Clinical Characteristics, Risk Factors and Prognosis - a Case-control Study
}

\section{Yuqi Zhang}

Zhengzhou University First Affiliated Hospital

\section{Wei Li}

Zhengzhou University First Affiliated Hospital

\section{Panpan Zhang}

Zhengzhou University First Affiliated Hospital

Jinyan Guo

Zhengzhou University First Affiliated Hospital

Jinlei Sun

Zhengzhou University First Affiliated Hospital

Jiameng Lu

Zhengzhou University First Affiliated Hospital

Shengyun Liu ( $\nabla$ fccliusy2@zzu.edu.cn )

Zhengzhou University First Affiliated Hospital https://orcid.org/0000-0002-0426-1705

\section{Research article}

Keywords: Systemic lupus erythematosus, hematological malignancies, risk factors, survival, prognosis

Posted Date: March 17th, 2021

DOl: https://doi.org/10.21203/rs.3.rs-313607/v1

License: (c) (i) This work is licensed under a Creative Commons Attribution 4.0 International License.

Read Full License

Version of Record: A version of this preprint was published at Arthritis Research \& Therapy on January 3rd, 2022. See the published version at https://doi.org/10.1186/s13075-021-02692-8. 


\section{Abstract}

Background: Systemic lupus erythematosus (SLE) is a chronic and complex multi-system autoimmune disorder. Higher risks of malignancy were observed in SLE patients, which was associated with higher mortality. We aimed to explore clinical characteristics, risk factors and prognosis between SLE patients with or without hematological malignancies (HM) in Chinese population.

Methods: We retrospectively collected patients from our hospital with a diagnosis of SLE from January 2013 to December 2020. Clinical and laboratory data were collected and disease activity was evaluated according to systemic lupus erythematosus disease activity index-2000 (SLEDAI-2K). Logistic regression analysis was performed to predict risk factors. The survival rate was estimated by Kaplan-Meier and Cox proportional hazards regression analysis.

Results: The study enrolled 15 SLE patients with HM as the case group and 57 without HM as the control group for analysis. The incidence rate of HM was approximately $0.24 \%$ with elevated standard incidence rate of lymphoma and leukemia (27.559 and 12.708, respectively). Patients with HM were at a higher age at the diagnosis of SLE, with a higher frequency of infection, splenomegaly and a lower level of hemoglobin compared with patients without HM. SLEDAI-2K was comparable between the two groups at the diagnosis of SLE $(P=0.184)$. Lower percentage of patients with HM expressed positive anti-dsDNA antibody $(26.7 \%$ vs $66.7 \% \bigotimes P=0.005)$ or had ever been treated with hydroxychloroquine $(40.0 \%$ vs $86.0 \%$, $P=0.001)$. Higher age $(O R 1.098, P=0.004)$, infection $(O R 5.759, P=0.041)$ and lower hemoglobin ( $O R$ $0.954, P=0.021)$ were risk factors for SLE patients to develop with HM. Female $(R R 0.219, P=0.009)$ and hydroxychloroquine $(R R 0.281, P=0.024)$ were protective factors from mortality.

Conclusions: SLE patients are more prone to be complicated with HM, especially for those at a higher age, suffering with infection or anemia. The prognosis of male patients with SLE tends to be poorer whether complicated with HM. The association between antinuclear antibody spectrum and SLE complicated with HM needs further investigation.

\section{Background}

Systemic lupus erythematosus (SLE) is one of common chronic and complex multi-system autoimmune disorders. This disorder occurs predominantly in the reproductive age women, with the female-to-male ratio approximately 10:1[1,2]. With early diagnosis and judicious therapy, including systemic glucocorticoids, immunosuppressive agents, and newly biological drugs, the survival rate of SLE has been significantly improved[3]. Study from a multisite international SLE cohort demonstrated a higher standardized mortality ratio compared to the general population, with particularly high mortality for circulatory disease, infection, renal disease, and malignancy[4]. Several studies have reported elevated cancer risks in SLE[5-14], especially hematological malignancies[11-21], which had an influence on the prognosis of patients $[4,11,22]$. Non-Hodgkin's lymphoma (NHL) is the most common type while other kinds of hematological malignancies, such as Hodgkin's lymphoma (HL), leukemia and possibly 
myeloma[14, 20], also at a higher risk for SLE compared with general population. However, the age-risk, gender-risk relationship and latency between hematological malignancies and SLE are still controversial[13, 18, 20, 23].

Hematological malignancies (HM) are a group of etiologically heterogeneous diseases. The mechanisms of SLE complicated with HM are still inconclusive, for which a generally accepted explanation is intrinsic immunological dysregulation combined with exposure to medications and virus[24-28]. However, elevated risks of treatment-induced malignancy are still in controversy $[5,11,15,16,29]$, partly because disease activity may influence the therapeutic choice resulting to difficulties in associating medications with malignancy[23,30]. Up to now, the characteristics and outcome of SLE patients with HM in Chinese population are still limited, and the association between antinuclear antibody spectrum and SLE complicated with $\mathrm{HM}$ is gaining extensive attention, so we performed a retrospective study to explore the clinical characteristics, laboratory parameters, as well as risk factors and prognosis in our tertiary institution.

\section{Methods}

\section{Study design}

We retrospectively collected all patients from our hospital with a diagnosis of SLE, as either a primary or a secondary diagnosis from January 2013 to December 2020. After excluding the repetitive cases, we identified patients who were diagnosed with $\mathrm{HM}$ as the case group (Group A), including leukemia, lymphoma, multiple myeloma and plasmacytoma. In order to avoid confounding factors, the control group (Group B) consisted of randomly selected patients without any kinds of malignancies, with three controls matching one case.

\section{Patient inclusion and exclusion criteria}

All patients were fulfilled the 1997 American College of Rheumatology (ACR) revised criteria for the classification of SLE [31]. Hematological malignancies were identified by biological pathology of bone marrow or tissue specimens according to respective diagnostic criteria[32-34]. SLE patients diagnosed with $\mathrm{HM}$ synchronously were defined as diagnosis of $\mathrm{HM}$ within 2-month duration of SLE diagnosis. More than 2-month interval was defined as SLE prior or posterior to HM. Patients younger than 18 or older than 80 years were excluded. Patients ever diagnosed with rheumatoid arthritis, ankylosing spondylitis, psoriatic arthritis, systemic sclerosis, inflammatory myopathy, Sjogren's syndrome and multiple connective tissue disease were also excluded.

\section{Clinical data and laboratory examinations}

Patient data, including age, sex, history of tumor, symptoms of onset, disease activity, treatment, outcome and survival time were collected. The follow-up was ended at the beginning of January, 2021. The disease activity was evaluated according to systemic lupus erythematosus disease activity index-2000 
(SLEDAI-2K)[35] at the baseline and diagnosis of HM. Laboratory examinations including routine blood analysis, liver function, kidney function, C-reactive protein (CRP), erythrocyte sedimentation rate (ESR), complement and autoantibody profile were collected when they were first diagnosed with SLE in our institution. All the medications since the day of SLE diagnosis to HM occurrence (Group A) or the end of follow-up (Group B) were retrieved from the medical records and follow-up.

\section{Statistical analysis}

Statistical analyses were performed using IBM SPSS Statistics version 25.0 software. For categorical variables, data are presented as frequencies (percentages), while for continuous variables, data are reported as means with standard deviation (SD) or median with inter-quartile range $\left(Q_{1}-Q_{3}\right)$. Normally distributed data between two groups were analyzed using independent-samples t-tests while nonnormally distributed data were analyzed using the rank sum test. Categorical data were analyzed using the chi-square test or Fisher's exact test. The data of sex- and age-stratified cancer incidence in general Chinese population were published by National Central Cancer Registry of China (NCCRC)[36]. The standardized incidence ratio (SIR) was calculated by dividing the observed malignant rate by the expected rate. Logistic regression analysis was performed to predict the risk factors. The survival rate was estimated by Kaplan-Meier and Cox proportional hazards regression analysis and survival curves were presented by GraphPad Prism (version 8). A two-tailed $P$-value $<0.05$ was considered statistically significant.

\section{Results}

\section{Patient characteristics}

A total of 7954 patients with a diagnosis of SLE were identified, with 879 males $(11.1 \%)$ and 7075 females. We excluded 266 patients who had ever been diagnosed with other rheumatoid diseases. 19 patients received a diagnosis of HM posterior to or synchronously with SLE. In order to control confounding factors, 136 patients ever diagnosed with other kinds of malignancies were excluded, so there were 7533 cancer-free patients eligible for analysis. With three controls matching one case, we enrolled 19 patients as the case group and 57 as the control group (Group B) (Fig 1). The data of 4 patients with HM when first diagnosed with SLE were incomplete, so only 15 were enrolled in analysis (Group A) at the baseline (Fig 1, Table 1-2). Demographic and clinical characteristics are shown in Table 1. Twelve (80\%) were female in Group A, with no difference from Group B (86\%). Age for patients in Group A were higher than that in Group B (52 (42-63) vs 31 (25-47), $P=0.002)$. None was reported a previous history of HM, while $10(66.7 \%)$ patients developed with HM synchronously with and 5 (33.3\%) posterior to SLE. Though only 6 patients reported family history of tumor, the frequency was higher in Group A than that in Group B (13.3\% vs $7.0 \%, P=0.034)$. For clinical features, patients in Group A had a higher frequency of infection $(60.0 \%$ vs $22.8 \%, P=0.014)$ and splenomegaly $(46.7 \%$ vs $15.8 \%, P=0.027)$ than Group B. Infection always involved respiratory system except for one suffering from panniculitis in the control group (data not shown). 
Table 1.

Clinical features of SLE patients with/without hematological malignancies

\begin{tabular}{|c|c|c|c|}
\hline Parameter & $\begin{array}{l}\text { Group A } \\
(n=15)\end{array}$ & $\begin{array}{l}\text { Group B } \\
(n=57)\end{array}$ & $P$-value \\
\hline Female $(n, \%)$ & $12(80.0)$ & $49 \llbracket 86.0 \rrbracket$ & 0.867 \\
\hline Age at SLE diagnosis (years), M (Q1-Q3) & $52(42-63)$ & $31(25-47)$ & $0.002^{\star}$ \\
\hline Age at HM diagnosis (years, mean \pm SD) & $52 \pm 15$ & - & - \\
\hline Lymphadenopathy (n, \%) & $9(60.0)$ & $26 \rrbracket 45.6 \rrbracket$ & 0.321 \\
\hline Fever (n, \%) & $9(60.0)$ & $21 \rrbracket 36.8 \rrbracket$ & 0.106 \\
\hline Infection (n, \%) & $9(60.0)$ & $13 \llbracket 22.8 \rrbracket$ & $0.014^{*}$ \\
\hline Hypertension (n, \%) & $1(6.7)$ & $9 \bigotimes 15.8 \rrbracket$ & 0.625 \\
\hline Diabetes mellitus (n, \%) & $0(0)$ & $1 \otimes 1.8 \rrbracket$ & 1.000 \\
\hline Dyslipidemia (n,\%) & $13(13 / 14,92.9)$ & $40(40 / 56,71.4)$ & 0.186 \\
\hline Smoking (n, \%) & $1(6.7)$ & $5 \rrbracket 8.8 \rrbracket$ & 1.000 \\
\hline Drinking $(\mathrm{n}, \%)$ & $1(6.7)$ & $2 \bowtie 3.5 \rrbracket$ & 1.000 \\
\hline Family history of tumor $(\mathrm{n}, \%)$ & $2(13.3)$ & $4 \otimes 7.0 \bigotimes$ & $0.034^{\star}$ \\
\hline Rash (n, \%) & $4(26.7)$ & $20 \bigotimes 35.1 \rrbracket$ & 0.538 \\
\hline Arthralgia $(n, \%)$ & $5(33.3)$ & $14 \llbracket 24.6 \rrbracket$ & 0.721 \\
\hline Pleural effusion $(n, \%)$ & $5(33.3)$ & $15 \llbracket 26.3 \rrbracket$ & 0.829 \\
\hline Pericardial effusion $(\mathrm{n}, \%)$ & $5(33.3)$ & $16 \llbracket 29.1 \rrbracket$ & 0.936 \\
\hline Splenomegaly $(\mathrm{n}, \%)$ & $7(46.7)$ & $9 \rrbracket 15.8 \rrbracket$ & $0.027 *$ \\
\hline
\end{tabular}

* Statistical significance $(P \otimes 0.05)$

Group A: SLE patients with hematological malignancies

Group B: SLE patients without hematological malignancies

Abbreviation: $\mathrm{HM}$, hematological malignancies. 
Table 2.

Laboratory parameters of SLE patients with/without $\mathrm{HM}$ at the baseline

\begin{tabular}{|c|c|c|c|}
\hline Parameters & $\begin{array}{l}\text { Group A } \\
(n=15)\end{array}$ & $\begin{array}{l}\text { Group B } \\
(n=57)\end{array}$ & $P$-value \\
\hline Hematological abnormality $(\mathrm{n}, \%)$ & $13(86.7)$ & $39(68.4)$ & 0.280 \\
\hline 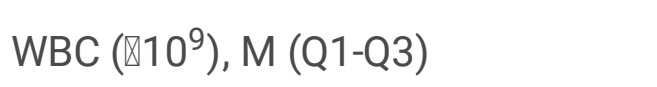 & $3.40(1.80-5.68)$ & $3.90(2.85-6.25)$ & 0.072 \\
\hline $\mathrm{RBC}\left(\mathbb{1} 10^{12}\right.$, mean $\left.\pm \mathrm{SD}\right)$ & $3.08 \pm 0.88$ & $3.59 \pm 0.64$ & $0.016^{\star}$ \\
\hline $\mathrm{Hb}(\mathrm{g} / \mathrm{L}$, mean $\pm \mathrm{SD})$ & $89.97 \pm 23.18$ & $103.43 \pm 20.41$ & $0.031 *$ \\
\hline 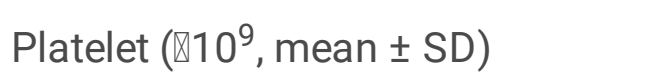 & $118.80 \pm 64.68$ & $160.54 \pm 82.66$ & 0.074 \\
\hline Urine protein positivity $(\mathrm{n}, \%)$ & $5(33.3)$ & $27(47.4)$ & 0.330 \\
\hline 24hTP(g), M (Q1-Q3) † & $0.49(0.29-1.13)$ & $1.40(0.36-4.92)$ & 0.156 \\
\hline Scr (umol/L), M (Q1-Q3) & $62.00(47.50-73.50)$ & $55.00(47.50-73.50)$ & 0.856 \\
\hline GFR (ml/min/1.73m2), M (Q1-Q3) & $85.57(77.04-109.31)$ & $108.76(91.70-121.71)$ & 0.099 \\
\hline $\mathrm{TP}(\mathrm{g} / \mathrm{L}$, mean $\pm \mathrm{SD})$ & $66.88 \pm 11.74$ & $64.72 \pm 13.16$ & 0.567 \\
\hline Albumin $(\mathrm{g} / \mathrm{L}$, mean $\pm \mathrm{SD})$ & $29.70 \pm 6.69$ & $31.72 \pm 7.58$ & 0.351 \\
\hline Globin $(\mathrm{g} / \mathrm{L}$, mean $\pm \mathrm{SD})$ & $37.18 \pm 13.39$ & $33.33 \pm 9.64$ & 0.310 \\
\hline Lupus nephritis (n, \%) & $5(33.3 \rrbracket$ & $28(49.1)$ & 0.275 \\
\hline TC (mmol/L), M (Q1-Q3) & $3.05(2.54-3.45)$ & $3.91(3.09-4.56)$ & $0.030 *$ \\
\hline TG (mmol/L), M (Q1-Q3) & $1.33(0.75-2.02)$ & $1.64(1.20-2.37)$ & 0.157 \\
\hline $\mathrm{HDL}(\mathrm{U} / \mathrm{L}), \mathrm{M}(\mathrm{Q} 1-\mathrm{Q} 3)$ & $0.61(0.42-0.69)$ & $0.96(0.77-1.16)$ & $0.003^{\star}$ \\
\hline LDL (U/L), M (Q1-Q3) & $1.74(1.11-2.34)$ & $2.39(1.67-2.95)$ & 0.058 \\
\hline $\operatorname{ALT}(\mathrm{U} / \mathrm{L}), \mathrm{M}(\mathrm{Q} 1-\mathrm{Q} 3)$ & $24.00(10.00-35.00)$ & $23.00(13.00-49.00)$ & 0.682 \\
\hline AST (U/L), M (Q1-Q3) & $29.00(17.00-58.00)$ & $28.00(18.00-56.50)$ & 0.950 \\
\hline $\mathrm{LDH}(\mathrm{U} / \mathrm{L}), \mathrm{M}(\mathrm{Q} 1-\mathrm{Q} 3)$ & $262.00(197.00-453.00)$ & $273.00(206.00-614.00)$ & 0.767 \\
\hline EBV-lgM+(n, \%) †† & $0(0)$ & $2(10)$ & 0.975 \\
\hline EBV-lgG+(n, \%) & $7(100)$ & $20(100)$ & - \\
\hline $\mathrm{C} 3(\mathrm{~g} / \mathrm{L}$, mean $\pm \mathrm{SD})$ & $0.78 \pm 0.35$ & $0.67 \pm 0.36$ & 0.314 \\
\hline $\mathrm{C} 4(\mathrm{~g} / \mathrm{L}$, mean $\pm \mathrm{SD})$ & $0.16 \pm 0.12$ & $0.13 \pm 0.08$ & 0.401 \\
\hline ESR (mm/h), M (Q1-Q3) & $48.00(34.50-100.25)$ & $41.50(19.75-74.00)$ & 0.533 \\
\hline
\end{tabular}




\begin{tabular}{|c|c|c|c|}
\hline CRP (mg/L), M (Q1-Q3) & $16.31(2.82-34.71)$ & $3.88(1.50-7.17)$ & $0.018 *$ \\
\hline Ferritin (ng/ml), M (Q1-Q3) ††† & $692.45(475.20-1248.28)$ & 188.85 (71.92-369.53) & $0.007 *$ \\
\hline SLEDAI-2K, M (Q1-Q3) & $9.00(4.00-14.00)$ & $12.00(8.00-18.00)$ & 0.184 \\
\hline ANA $(n, \%)$ & $15(100)$ & $57(100)$ & - \\
\hline Anti-dsDNA antibody (n, \%) & $4(26.7)$ & $38(66.7)$ & $0.005^{\star}$ \\
\hline Anti-Smith antibody $(\mathrm{n}, \%)$ & $5(5 / 11,45.5)$ & 19ه19/50, 38.0ه & 0.907 \\
\hline Anti-Rib P (n, \%) & $4 \rrbracket 4 / 14,28.6 \rrbracket$ & $26 \rrbracket 26 / 54,48.1 \rrbracket$ & 0.189 \\
\hline Anti-Nuc (n, \%) & $5 \rrbracket 5 / 12,41.7 \rrbracket$ & $31(31 / 55,56.4 \rrbracket$ & 0.355 \\
\hline Anti-His (n, \%) & $3 \otimes 3 / 13,23.1 \rrbracket$ & $25 \llbracket 25 / 54,46.3 \rrbracket$ & 0.128 \\
\hline Anti-SSA/Ro52 (n, \%) & $9 \otimes 9 / 13,69.2 \rrbracket$ & $24 \rrbracket 24 / 52,46.2 \rrbracket$ & 0.137 \\
\hline Anti-SSA/Ro60 (n, \%) & $8 \rrbracket 8 / 12,66.7 \rrbracket$ & $26 \rrbracket 26 / 49,53.1 \rrbracket$ & 0.395 \\
\hline Anti-SSB $(n, \%)$ & $4 \rrbracket 4 / 12,33.3 \rrbracket$ & $9 \otimes 9 / 53,17.0 \rrbracket$ & 0.379 \\
\hline $\operatorname{ACA}(n, \%)$ & $2 \varangle 2 / 8,25.0 \rrbracket$ & $2 \rrbracket 2 / 49,4.1 \rrbracket$ & 0.161 \\
\hline $\operatorname{APL}(n, \%)$ & $4 \llbracket 4 / 7,57.1 \rrbracket$ & $15 \rrbracket 15 / 27,55.6 \rrbracket$ & 1.000 \\
\hline
\end{tabular}

* Statistical significance ( $P \otimes 0.05)$

Group A: SLE patients with hematological malignancies

Group B: SLE patients without hematological malignancies

Hematological abnormality: Patients present with leukopenia $\left(\mathrm{WBC} \otimes 3.0 \otimes 10^{9}\right)$, anemia or thrombocytopenia.

Lupus nephritis: 24 -hour total urinary protein $\geq 0.5 \mathrm{~g}$ or the confirmation of renal biopsy before the end of follow-up.

† The data of Group A (7 patients) and Group B (29 patients).

t† EBV-IgM and EBV-lgG were both the data of Group A (7 patients) and Group B (20 patients).

††† The data of Group A (6 patients) and Group B (20 patients).

Abbreviation: $\mathrm{HM}$, hematological malignancies; WBC, white blood cell; $\mathrm{RBC}$, red blood cell; $\mathrm{Hb}$, hemoglobin; 24hTP, 24-hour total urinary protein; Scr, serum creatinine; GFR, glomerular filtration rate; TP, total protein; TC, total cholesterol; TG, triglyceride; HDL, high-density lipoprotein; LDL, low-density lipoprotein; $A L T$, alanine transaminase; $A S T$, aspartate transaminase; $L D H$, lactic dehydrogenase; $E B V$, Epstein-Barr virus; CMV, cytomegalovirus; ESR, erythrocyte sedimentation rate; CRP, C-reactive protein; 
SLEDAI-2K, systemic lupus erythematosus disease activity index-2000; ANA, anti-nuclear antibody; AntiRib P, Anti-ribosomal P-protein antibody; Anti-Nuc, Anti-nucleosome antibody; Anti-His, Anti-histone antibody; ACA, Anti-centromere antibody; APL, Anti-phospholipid antibody.

\section{Laboratory findings}

Baseline laboratory parameters of SLE patients with or without HM were shown in Table 2. Majority of patients in both groups suffered from hematological abnormality ( $86.7 \%$ vs $68.4 \%, P=0.280$ ), including leukocytopenia, thrombocytopenia or anemia. Both groups tended to suffer from anemia while patients in Group A had a lower level of hemoglobin. Dyslipidemia was found more frequently in Group A, especially high-density lipoprotein, while C-reactive protein and ferritin were significantly higher comparing with Group B. As for the expression of autoantibodies, anti-nuclear antibody presented positively in all the patients at the baseline. Lower percentage of patients in Group A expressed anti-dsDNA antibody (26.7\% vs $66.7 \%, P=0.005$ ), while percentage of patients with positive anti-ribosomal P-protein antibody, antinucleosome antibody and anti-histone antibody were comparable between the two groups. The ratio of CD4+/CD8+ T cell $(0.54(0.48-0.79)$ vs $0.92(0.57-1.34), P=0.080)$ and percentage of B cell $(9.06 \pm 7.43$ vs $19.49 \pm 14.45, P=0.137$, Table 3 ) seemed to be lower in Group A while still need further confirmation. Disease activity estimated by SLEDAI-2K at the diagnosis of SLE did not show significant difference between the two groups (9.00 (4.00-14.00) vs $12.00(8.00-18.00), P=0.184)$.

Table 3.

The lymphocyte subsets of SLE with/without hematological malignancies

\begin{tabular}{|llll|}
\hline Lymphocyte subsets (\%) & $\begin{array}{l}\text { Group A } \\
(\mathbf{n}=15)\end{array}$ & $\begin{array}{l}\text { Group B } \\
(\mathbf{n}=57)\end{array}$ & $P$-value \\
\hline CD3+ T cell & $68.90 \pm 17.56$ & $70.48 \pm 13.42$ & 0.735 \\
\hline CD3+CD8+ T cell & $39.26 \pm 7.97$ & $34.87 \pm 12.27$ & 0.546 \\
\hline CD3+CD4+ T cell & $24.48 \pm 11.04$ & $34.72 \pm 15.30$ & 0.164 \\
\hline CD4+/CD8+ T cell (M, Q1-Q3) & $0.54(0.48-0.79)$ & $0.92(0.57-1.34)$ & 0.080 \\
\hline NK cell (CD16+CD56+) & $21.38 \pm 21.72$ & $12.62 \pm 9.75$ & 0.425 \\
\hline B cell (CD19+) & $9.06 \pm 7.43$ & $19.49 \pm 14.45$ & 0.137 \\
\hline
\end{tabular}

Group A: SLE patients with hematological malignancies

Group B: SLE patients without hematological malignancies

† The data of lymphocyte subsets were from Group A (5 patients) and Group B (22 patients)

\section{Distribution of hematological malignancies and SIR}


Of fifteen patients with HM (Additional file1, Supplementary Table 1), ten patients developed HM synchronously with SLE while five posterior to SLE. Four patients $(26.7 \%)$ were diagnosed with acute myeloid leukemia (AML), seven (46.7\%) NHL, with diffuse large B-cell lymphoma (DLBCL) accounting for more than a half, two (13.3\%) HL and two multiple myeloma (MM).

In the total of 7954 SLE patients in our institution from 2013 to 2020, nineteen patients were diagnosed with HM (Additional file1, Supplementary Table 1)), with the incidence rate of approximately $0.24 \%$. There was a significantly increased SIR of lymphoma (27.559, 95\% C/10.437-72.766) and leukemia (12.708, 95\% Cl 4.086-39.524). Among them, three were male, accounting for $0.34 \%$ (3/879) while female for $0.23 \%(16 / 7075)$ when it comes to gender difference of incidence in SLE patients with HM.

\section{Risk factors of hematological malignancies in patients with SLE}

Based on the baseline comparison above, odds ratio (OR) was calculated by univariate and multivariate logistic analysis to explore risk or protective factors of SLE complicated with HM (Table 4). In univariate logistic analysis, older age at SLE diagnosis (OR 1.075, 95\% $C / 1.028-1.125, P=0.002)$, infection (OR $5.077,95 \% C / 1.523-16.925, P=0.008)$ and high levels of ferritin $(O R 1.003,95 \% C / 1.000-1.005, P=0.033)$ were risk factors of developing with $\mathrm{HM}$, while high levels of hemoglobin $(O R 0.970,95 \% \mathrm{Cl}$ 0.945-0.998, $P$ $=0.038)$, anti-dsDNA antibody $(O R 0.182,95 \% \mathrm{Cl} 0.051-0.647, P=0.009)$ and hydroxychloroquine application $(O R 0.143,95 \% \mathrm{Cl} 0.041-0.504, P=0.002)$ might play a protective role. In multivariate analysis, older age at SLE diagnosis (OR1.098,95\% Cl1.031-1.170, $P=0.004)$ and infection $(O R 5.759,95 \% \mathrm{Cl}$ 1.077-30.804, $P=0.041)$ were risk factors while high levels of hemoglobin $(O R 0.954,95 \% C / 0.917-0.993$, $P=0.021)$ was potentially a protective factor.

Table 4.

Risk factors for hematological malignancies development in patients with SLE

\begin{tabular}{|c|c|c|c|c|}
\hline \multirow[t]{2}{*}{ Parameter } & \multicolumn{2}{|c|}{ Univariate logistic analysis } & \multicolumn{2}{|c|}{ Multivariate logistic analysis } \\
\hline & ORD $95 \%$ Cl & $P$-value & ORD $95 \%$ CI & $P$-value \\
\hline Age at SLE diagnosis & $1.075(1.028-1.125)$ & $0.002^{\star}$ & $1.098(1.031-1.170)$ & $0.004^{*}$ \\
\hline Infection & $5.077(1.523-16.925)$ & $0.008^{*}$ & $5.759(1.077-30.804)$ & $0.041 *$ \\
\hline Hemoglobin & $0.970(0.945-0.998)$ & $0.038^{*}$ & $0.954(0.917-0.993)$ & $0.021^{*}$ \\
\hline Ferritin & $1.003(1.000-1.005)$ & $0.033^{*}$ & - & - \\
\hline Anti-dsDNA antibody & $0.182(0.051-0.647)$ & $0.009 *$ & $0.230(0.044-1.219)$ & 0.084 \\
\hline SLEDAI-2K at SLE diagnosis & $0.952(0.873-1.038)$ & 0.264 & - & - \\
\hline Glucocorticoids & $0.361(0.055-2.388)$ & 0.291 & - & - \\
\hline Mycophenolate mofetil & $0.308(0.063-1.505)$ & 0.146 & - & - \\
\hline Hydroxychloroquine & $0.143(0.041-0.504)$ & $0.002^{*}$ & $0.221(0.043-1.135 \rrbracket$ & 0.071 \\
\hline
\end{tabular}


* Statistical significance $(P \otimes 0.05)$

Abbreviation: SLEDAl-2K, systemic lupus erythematosus disease activity index-2000.

\section{Treatment and prognosis}

Table 5.

Treatment for SLE with/without hematological malignancies

\begin{tabular}{|llll|}
\hline Medication & $\begin{array}{l}\text { Group A } \\
(\mathbf{n}=15)\end{array}$ & $\begin{array}{l}\text { Group B } \\
(\mathrm{n}=57)\end{array}$ & $P$-value \\
\hline Glucocorticoids (n, \%) & $13(86.7)$ & $54(94.7)$ & 0.601 \\
\hline Pulse therapy of glucocorticoids (n, \%) & $2(13.3)$ & $7(12.3)$ & 1.000 \\
\hline IVIG (n, \%) & $3(20.0)$ & $17(29.8)$ & 0.666 \\
\hline Cyclophosphamide (n, \%) & $0(0)$ & $9(15.8)$ & 0.228 \\
\hline Mycophenolate mofetil (n, \%) & $2(13.3)$ & $19(33.3)$ & 0.231 \\
\hline Methotrexate (n, \%) & $0(0)$ & $2(3.5)$ & 1.000 \\
\hline Leflunomide (n, \%) & $0(0)$ & $5(8.8)$ & 0.536 \\
\hline Azathioprine (n, \%) & $1(6.7)$ & $2(3.5)$ & 1.000 \\
\hline Cyclosporin (n, \%) & $0(0)$ & $2(3.5)$ & 1.000 \\
\hline Tacrolimus (n, \%) & $1(6.7)$ & $6(10.5)$ & 1.000 \\
\hline Thalidomide (n, \%) & $2(10.5)$ & $1(1.8)$ & 0.204 \\
\hline Hydroxychloroquine (n, \%) & $6(40.0)$ & $49(86.0)$ & $0.001 *$ \\
\hline Rituximab (n, \%) & $0(0)$ & $3(5.3)$ & 0.856 \\
\hline Belizumab (n, \%) & $0(0)$ & $1(1.8)$ & 1.000 \\
\hline
\end{tabular}

Table 5 shows all the medications since the day of SLE diagnosis to hematological malignancies occurrence (Group A) or the end of follow-up (Group B).

Group A: SLE with hematological malignancies

Group B: SLE without hematological malignancies

* Statistical significance $(P \otimes 0.05)$

Abbreviation: IVIG, intravenous immunoglobin. 
Treatment strategies were displayed in Table 5. Thirteen (86.7\%) patients in Group A and fifty-four $(94.7 \%)$ in Group B received glucocorticoids, with no statistical significance. For patients in Group A, none had ever been exposed to cyclophosphamide (CYC) prior to the diagnosis of HM while nine $(15.8 \%)$ in Group B were ever given CYC treatment. Lower percentage of patients in Group A were treated with hydroxychloroquine (HCQ) than that in Group B $(40.0 \%$ vs $86.0 \%, P=0.001)$. The cumulative probability of survival analyzed by Kaplan-Meier methods was shown in Fig. 2. Up to January, 2021, the median follow-up periods were both 22.50 months in the two groups and the median survival time for Group $A$ was 30 months from SLE diagnosis and 15 months from HM diagnosis. Patients in Group B had a significantly better prognosis than that in Group $\mathrm{A}(P=0.0037)$. Male tended to have a worse prognosis no matter if they were complicated with $\mathrm{HM}$. The risk factors of mortality were estimated by Cox regression (Table 6) showing that female $(R R 0.219, P=0.009)$ and hydroxychloroquine $(R R 0.281, P=$ 0.024 ) might be protective factors. Main cause of death as we collected was multiple organ failure due to malignancy itself or pulmonary infection.

Table 6.

Multivariate proportional hazards Cox regression on risk factors of mortality in patients with SLE

\begin{tabular}{|lll|}
\hline Parameter & $R R(95 \%$ Cl & $P$-value \\
\hline Gender (female) & $0.219(0.070-0.681)$ & $0.009^{*}$ \\
\hline Age at SLE diagnosis & $1.024(0.984-1.065)$ & 0.242 \\
\hline Hematological malignancy & $1.471(0.354-6.107)$ & 0.595 \\
\hline Hydroxychloroquine & $0.281(0.094-0.845)$ & $0.024^{\star}$ \\
\hline
\end{tabular}

* Statistical significance $(P \otimes 0.05)$

Abbreviation: SLE, systemic lupus erythematosus.

\section{Discussion}

We performed a case-control study retrospectively to explore clinical characteristics, risk factors and prognosis of SLE patients complicated with HM in our institution. SLE patients were at a significantly increased risk to develop with HM after a shorter latency of SLE diagnosis in our study. Gender difference was presented in HM incidence rate and mortality that male tended to have a higher risk. Older age, infection and lower hemoglobin at the baseline tended to be risk factors for SLE patients developing with $\mathrm{HM}$ while if autoantibodies, especially anti-dsDNA could play a protective role in HM development still need further confirmation.

Significant increased SIRs of leukemia and lymphoma, consisting of $\mathrm{NHL}, \mathrm{HL}, \mathrm{MM}$ and plasmacytoma for the latter were proved in SLE patients of our study compared with reported incidence of HM in general Chinese population[36]. NHL was the most common type as other studies[6,37] and DLBCL, a relatively 
aggressive type, accounted for more than a half of $\mathrm{NHL}$ in our study. All the leukemia cases we collected were AML, which was illustrated in a large nationwide data that only AML was at an increased risk of SLE patients[21]. Most patients in our study diagnosed with HM within two-month latency of SLE, which was confirmed in a nationwide cohort in Taiwan[13] and an international cohort study[6] that the risk ratio of hematological cancers decreased with time, with the highest risk in the first year after SLE diagnosis. For $\mathrm{NHL}$, malignant $\mathrm{B}$ cells may produce immunoglobulin with autoantibody features[11]. Besides, the symptoms of lymphoma may mimic SLE, like fever, arthralgia, and lymphadenopathy, so if the symptoms are unusually severe or persistent, biopsy of bone marrow or lymph nodes is necessary to clarify if a malignancy has occurred.

The prevalence of HM and mortality was higher in male than that in female, in accord with previous studies[13, 23, 37, 38] while SLE was more frequent for female, so male may need more vigilance during the follow-up. Higher age at the diagnosis of SLE was a risk factor shown in our study, in accord with some previous studies $[5,39]$ but in conflict with a study from Taiwan that younger patients had a greater risk ratio of cancer[13]. However, for SLE patients complicated with HM, patients between 40-69 years had the highest SIR[13], which was comparable with our patients. Higher level of hemoglobin was inferred to have a protective effect on the risk of HM development in our study, while a nested casecontrol study also indicated that hematologic aberrations (leukocytopenia/thrombocytopenia or hematologic anemia) were associated with NHL in SLE patients[29]. The reasons of anemia can be different, with a common reason of hemolytic anemia in SLE. Hemminki et al[21] concluded that autoimmune hemolytic anemia was correlated with increased risk for lymphoma and leukemia. However, non-hemolytic anemia associated with HM need to be further studied. Ferritin, as an acute phase reactant, can be elevated in SLE. However, hyperferritinemia is more common in infection and malignancy[40,41]. So, if ferritin is abnormally high, we should be vigilant to exclude malignancy or infection.

Different theories have tried to explain possible links between the development of HM in SLE patients. A generally accepted explanation is intrinsic immunological dysregulation in SLE combined with external exposure. Dysregulation of both the innate and adaptive immune system might be associated with an increased risk of malignancies[21]. Theander et al[42] illustrated that CD4 + T lymphocytopenia and a low $\mathrm{CD} 4+/ \mathrm{CD} 8+\mathrm{T}$ cell ratio $\leq 0.8$ were predictors of lymphoma in pSS. We also observed a lower CD4+/CD8 $+T$ cell ratio in SLE patients with HM. However, we were failed to clarify a significant difference might be due to the small number of relative data. Infectious pathogens like virus and bacteria may be regarded as chronic stimulation to immune system. A nationwide cohort study suggested a viral cause such as Epstein-Barr virus (EBV) as a trigger for lymphoproliferation in SLE patients developing NHL[43]. However, we were unable to clarify the relationship between EBV and HM development in SLE patients because of ubiquity of EBV-IgG in peripheral blood of our patients.

The influence of medications is still in debate. Some researches suggested an increased risk for lymphoma associated with corticosteroids, especially high cumulative steroids[23], probably due to high disease activity or severity of the underlying disease[44], so it may be too arbitrary to draw a conclusion 
between steroid treatment and lymphoma. Hsu et al[45] illustrated that higher cumulative CYC dose and lower HCQ dose were associated with higher cancer risks. Ertz-Archambault et al[46] found azathioprine exposure was associated with a 7-fold risk for myeloid neoplasm. Several studies launched the hypothesis of a protective action of antimalarials like HCQ against cancer in patients with SLE[9, 47] but we did not observe an association between medications and HM development. Though HCQ showed a protective effect on decreasing risks of $\mathrm{HM}$ and mortality in the analysis, majority of patients with $\mathrm{HM}$ were diagnosed synchronously with SLE, so the treatment stragedy of SLE might be affected resulting to vacancy of HCQ use.

Antinuclear antibodies (ANAs) are a spectrum of autoantibodies that react with various nuclear and cytoplasmic components of cells, including anti-dsDNA, anti-histone, anti-Sm, anti-SSA/SSB, etc. ANAs may have anti-tumour activity and could be mediated by antibody-dependent cell-mediated cytotoxicity[48]. Several studies have confirmed the existence of ANAs in different types of tumor, with no conclusion of increased risks in developing specific tumor for SLE patients [48]. Combining in vivo with in vitro study, Lü et al[49] illustrated that anti-dsDNA antibodies have inhibitory effect on tumor cells via inducing apoptosis. Hansen et al[50] demonstrated that anti-DNA antibodies might have direct anticancer effects in cells with DNA repair defects. Our study also showed SLE patients with HM have a lower positive rate of anti-dsDNA and in univariate logistic analysis, anti-dsDNA showed a protective effect from developing with $\mathrm{HM}$, which was also implied in some studies before[29]. However, the association between ANAs and risks of HM development is still inconclusive and need further confirmation.

There are some limitations of our study. First, it's a single-center study from a relatively small cohort in China. Second, due to the retrospective nature of the study, we had to rely on medical records to obtain patients' symptoms and medications. Third, the follow-up time was not long enough though the survival disparity has been shown. However, we have done a detailed analysis between SLE patients with or without HM about clinical characteristics, risk factors and outcome in our hospital, which may remind more clinicians to be concerned about HM during SLE follow-up.

\section{Conclusions}

SLE patients have an increased risk of developing with hematological malignancies than general population, especially for those at a higher age, suffering with infection or anemia. The prognosis of male patients with SLE tends to be poorer whether complicated with HM. The protective role of hydroxychloroquine in HM occurence and mortality of SLE patients, and the impact of autoantibodies and lymphocytes on the development of HM still need further confirmation.

\section{Abbreviations}

ANAs: Antinuclear antibodies

AML: Acute myeloid leukemia 
CYC: Cyclophosphamide

DLBCL: Diffuse large B-cell lymphoma

EBV: Epstein-Barr virus

HCQ: Hydroxychloroquine

HL: Hodgkin's lymphoma

HM: Hematological malignancies

MALT: Mucosa-associated lymphoid tissue

MM: Multiple myeloma

NCCRC: National Central Cancer Registry of China

NHL: Non-Hodgkin's lymphoma

OR: Odds ratio

RA: Rheumatoid arthritis

RR: Risk ratio

SD: Standard deviation

SIR: Standardized incidence ratio

SLE: Systemic lupus erythematosus

SLEDAI-2K: Systemic lupus erythematosus disease activity index-2000

SS: Sjogren's syndrome

\section{Declarations}

\section{Availability of data and materials}

Available data and methodological information for this study are included in this article and accompanying supplementary materials.

\section{Ethics approval and consent to participate}

The study was approved by Committee on scientific research and ethics of the First Affiliated Hospital of Zhengzhou University with the reference number of 2019-KY-199. 


\section{Consent for publication}

Not applicable

\section{Competing interests}

The authors declare that they have no competing interests.

\section{Funding}

This study is supported by the project of tackling key problems of medical science and technology in Henan Province in the design of the study and data collection.

\section{Authors' contributions}

S-Y L designed the study and reviewed the manuscript. Y-Q Z carried out the data collection, data analysis and wrote the manuscript. W L, P-P Z and J-Y G participated in the design of the study and reviewed the manuscript. J-L S and J-M L reviewed the analysis and manuscript. All authors read and approved the final manuscript.

\section{Acknowledgements}

None

\section{References}

1. Somers EC, Marder W, Cagnoli P, Lewis EE, DeGuire P, Gordon C, et al. Population-based incidence and prevalence of systemic lupus erythematosus $\square$ the michigan lupus epidemiology and surveillance program. ARTHRITIS \& RHEUMATOLOGY 2014;66:369-78.

2. Li M, Zhang W, Leng X, Li Z, Ye Z, Li C, et al. Chinese sle treatment and research group (cstar) registry: I. Major clinical characteristics of chinese patients with systemic lupus erythematosus. Lupus 2013;22:1192-9.

3. Urowitz MB, Gladman DD, Tom BD, Ibanez D, Farewell VT. Changing patterns in mortality and disease outcomes for patients with systemic lupus erythematosus. J Rheumatol 2008;35:2152-8.

4. Bernatsky S, Boivin JF, Joseph L, Manzi S, Ginzler E, Gladman DD, et al. Mortality in systemic lupus erythematosus. Arthritis Rheum 2006;54:2550-7.

5. Pettersson T, Pukkala E, Teppo L, Friman C. Increased risk of cancer in patients with systemic lupus erythematosus. 1992.

6. Bernatsky S, Boivin JF, Joseph L, Rajan R, Zoma A, Manzi S, et al. An international cohort study of cancer in systemic lupus erythematosus. Arthritis Rheum 2005;52:1481-90.

7. Parikh-Patel A, White RH, Allen M, Cress R. Cancer risk in a cohort of patients with systemic lupus erythematosus (sle) in california. Cancer Causes Control 2008;19:887-94. 
8. Ladouceur A, Clarke AE, Ramsey-Goldman R, Bernatsky S. Malignancies in systemic lupus erythematosus: An update. Curr Opin Rheumatol 2019;31:678-81.

9. Guo JY, Ren ZG, Xuan YY, Li TF, Liu XJ, Niu CZ, et al. Clinical characteristics and risk factors of patients with systemic lupus erythematosus and cancer. Zhonghua Nei Ke Za Zhi 2020;59:218-21.

10. Bjornaîdal L, Lofstrom B, Yin L, Lundberg IE, Ekbom A. Increased cancer incidence in a swedish cohort of patients with systemic lupus erythematosu. Lupus 2002;31:66-71.

11. Tarr T, Gyorfy B, Szekanecz E, Bhattoa HP, Zeher M, Szegedi G, et al. Occurrence of malignancies in hungarian patients with systemic lupus erythematosus: Results from a single center. Ann NY Acad Sci 2007;1108:76-82.

12. Smedby KE, Hjalgrim H, Askling J, Chang ET, Gregersen H, Porwit-MacDonald A, et al. Autoimmune and chronic inflammatory disorders and risk of non-hodgkin lymphoma by subtype. J Natl Cancer Inst 2006;98:51-60.

13. Chen YJ, Chang YT, Wang CB, Wu CY. Malignancy in systemic lupus erythematosus: A nationwide cohort study in taiwan. Am J Med 2010;123:1150 e1-6.

14. Cao L, Tong H, Xu G, Liu P, Meng H, Wang J, et al. Systemic lupus erythematous and malignancy risk: A meta-analysis. PLoS One 2015;10:e0122964.

15. S.M.Sultan, loannou Y, D.A.Isenberg. Is there an association of malignancy with sleखan analysis of 276 patients under longterm review. Rheumatology 2000;39:1147-52.

16. Cibere J, Sibley J, Haga M. Systemic lupus erythematosus and the risk of malignancy. 2001.

17. Nived O, Bengtsson A, AJoÈnsen, Sturfelt G, Olsson H. Malignancies during follow-up in an epidemiologically defined systemic lupus erythematosus inception cohort in southern sweden. Lupus 2001;10:500-4.

18. Lin YC, Yen JH, Chang SJ, Lin YC. The age-risk relationship of haematologic malignancies in female patients with systemic lupus erythematosus: A nationwide retrospective cohort study. Lupus 2012;21:1250-6.

19. Tallbacka KR, Pettersson T, Pukkala E. Increased incidence of cancer in systemic lupus erythematosus: A finnish cohort study with more than 25 years of follow-up. Scand J Rheumatol 2018;47:461-4.

20. Apor E, O'Brien J, Stephen M, Castillo JJ. Systemic lupus erythematosus is associated with increased incidence of hematologic malignancies: A meta-analysis of prospective cohort studies. Leukemia Research 2014;38:1067-71.

21. Hemminki K, Huang W, Sundquist J, Sundquist K, Ji J. Autoimmune diseases and hematological malignancies: Exploring the underlying mechanisms from epidemiological evidence. Semin Cancer Biol 2020;64:114-21.

22. Moss KE, loannou Y, Sultan SM, Haq I, Isenberg DA. Outcome of a cohort of 300 patients with systemic lupus erythematosus attending a dedicated clinic for over two decades. Ann Rheum Dis 2002;61:409-13. 
23. Bernatsky S, Ramsey-Goldman R, Joseph L, Boivin J-F, Costenbader KH, Urowitz MB, et al. Lymphoma risk in systemic lupus: Effects of disease activity versus treatment. Annals of the Rheumatic Diseases 2014;73:138-42.

24. Boddu PC, Zeidan AM. Myeloid disorders after autoimmune disease. Best Pract Res Clin Haematol 2019;32:74-88.

25. Kiss E, Kovacs L, Szodoray P. Malignancies in systemic lupus erythematosus. Autoimmun Rev 2010;9:195-9.

26. Bernatsky S, Clarke A, Ramsey-Goldman R. Malignancy and systemic lupus erythematosus. Curr Rheumatol Rep 2002;4:351-8.

27. Zintzaras $E$, Voulgarelis $M$, Moutsopoulos HM. The risk of lymphoma development in autoimmune diseases_a meta-analysis. Arch Intern Med 2005;165:2337-44.

28. Ehrenfeld M, Abu-Shakra M, Buskila D, Shoenfeld Y. The dual association between lymphoma and autoimmunity. Blood Cells Mol Dis 2001;27:750-6.

29. Lofstrom B, Backlin C, Sundstrom C, Ekbom A, Lundberg IE. A closer look at non-hodgkin's lymphoma cases in a national swedish systemic lupus erythematosus cohort: A nested case-control study. Ann Rheum Dis 2007;66:1627-32.

30. Hansen A, Lipsky PE, Dorner T. B-cell lymphoproliferation in chronic inflammatory rheumatic diseases. Nat Clin Pract Rheumatol 2007;3:561-9.

31. Hochberg MC. Updating the american college of rheumatology revised criteria for the classification of systemic lupus erythematosus. Arthritis \& Rheumatism 1997;40: 1725-34.

32. Vardiman JW, Thiele J, Arber DA, Brunning RD, Borowitz MJ, Porwit A, et al. The 2008 revision of the world health organization (who) classification of myeloid neoplasms and acute leukemia: Rationale and important changes. Blood 2009;114:937-51.

33. Jaffe ES. The 2008 who classification of lymphomas: Implications for clinical practice and translational research. American Society of Hematology 2009:523-31.

34. Arber DA. The 2016 who classification of acute myeloid leukemia: What the practicing clinician needs to know. Seminars in Hematology 2019;56:90-5.

35. GLADMAN DD, IBAÑEZ D, UROWITZ MB. Systemic lupus erythematosus disease activity index 2000. The Journal of Rheumatology 2002;29:288-91.

36. Chen W, Sun K, Zheng R, Zeng H, Zhang S, Xia C, et al. Cancer incidence and mortality in china, 2014. Chin J Cancer Res 2018;30:1-12.

37. Bernatsky S, Ramsey-Goldman R, Labrecque J, Joseph L, Boivin JF, Petri M, et al. Cancer risk in systemic lupus: An updated international multi-centre cohort study. J Autoimmun 2013;42:130-5.

38. Zhang S, Ye Z, Li C, Li Z, Li X, Wu L, et al. Chinese systemic lupus erythematosus treatment and research group (cstar) registry $x_{\text {_ }}$ gender impact on long-term outcomes. Lupus 2019;0:1-7.

39. Ekstrom Smedby K, Vajdic CM, Falster M, Engels EA, Martinez-Maza O, Turner J, et al. Autoimmune disorders and risk of non-hodgkin lymphoma subtypes: A pooled analysis within the interlymph 
consortium. Blood 2008;111:4029-38.

40. Moore $\mathrm{C}$, Jr., Ormseth M, Fuchs $\mathrm{H}$. Causes and significance of markedly elevated serum ferritin levels in an academic medical center. J Clin Rheumatol 2013;19:324-8.

41. Senjo H, Higuchi T, Okada S, Takahashi O. Hyperferritinemia: Causes and significance in a general hospital. Hematology 2018;23:817-22.

42. Theander E. Lymphoma and other malignancies in primary sjogren's syndrome: A cohort study on cancer incidence and lymphoma predictors. Annals of the Rheumatic Diseases 2006;65:796-803.

43. MELLEMKJER L, ANDERSEN V, LINET MS, GRIDLEY G, HOOVER. R, OLSEN JRH. Non-hodgkin's lymphoma and other cancel among a cohort of patients with systemic lupus erythematosus. Arthritis Rheum 1997;40:761-8.

44. Engels EA, Cerhan JR, Linet MS, Cozen W, Colt JS, Davis S, et al. Immune-related conditions and immune-modulating medications as risk factors for non-hodgkin's lymphoma: A case-control study. Am J Epidemiol 2005;162:1153-61.

45. Hsu CY, Lin MS, Su YJ, Cheng TT, Lin YS, Chen YC, et al. Cumulative immunosuppressant exposure is associated with diversified cancer risk among 14832 patients with systemic lupus erythematosus: A nested case-control study. Rheumatology (Oxford) 2017;56:620-8.

46. Ertz-Archambault N, Kosiorek H, Taylor GE, Keleme K, Dueck A, Castro J, et al. Association of therapy for autoimmune disease with myelodysplastic syndromes and acute myeloid leukemia. JAMA Oncol 2017;3:936-43.

47. Ruiz-Irastorza G, Ugarte A, Egurbide MV, Garmendia M, Pijoan JI, Martinez-Berriotxoa A, et al. Antimalarials may influence the risk of malignancy in systemic lupus erythematosus. Ann Rheum Dis 2007;66:815-7.

48. Vlagea A, Falagan S, Gutierrez-Gutierrez G, Moreno-Rubio J, Merino M, Zambrana F, et al. Antinuclear antibodies and cancer: A literature review. Crit Rev Oncol Hematol 2018;127:42-9.

49. Lü S, Zhang J-p, Wu H-s, Zheng X-j, Chu Y-w, Xiong S-d. Anti-tumor effect of anti-dsdna autoantibodies Chin J Oncol 2005;27:73-6.

50. Hansen JE, Chan G, Liu Y, Hegan DC, Dalal S, Dray E, et al. Targeting cancer with a lupus autoantibody. Sci Transl Med 2012;4.

\section{Figures}




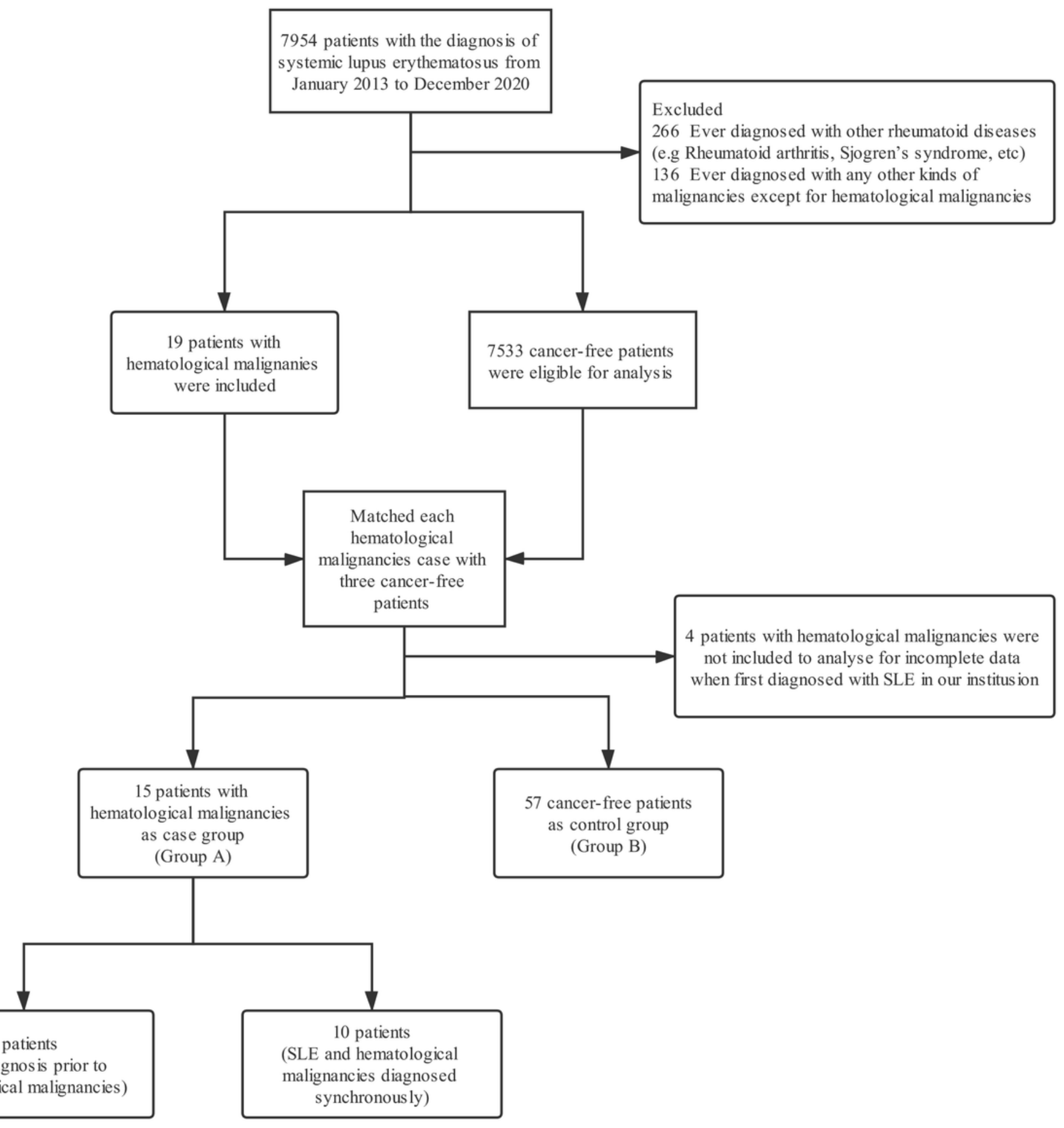

\section{Figure 1}

Flow chart of study design 


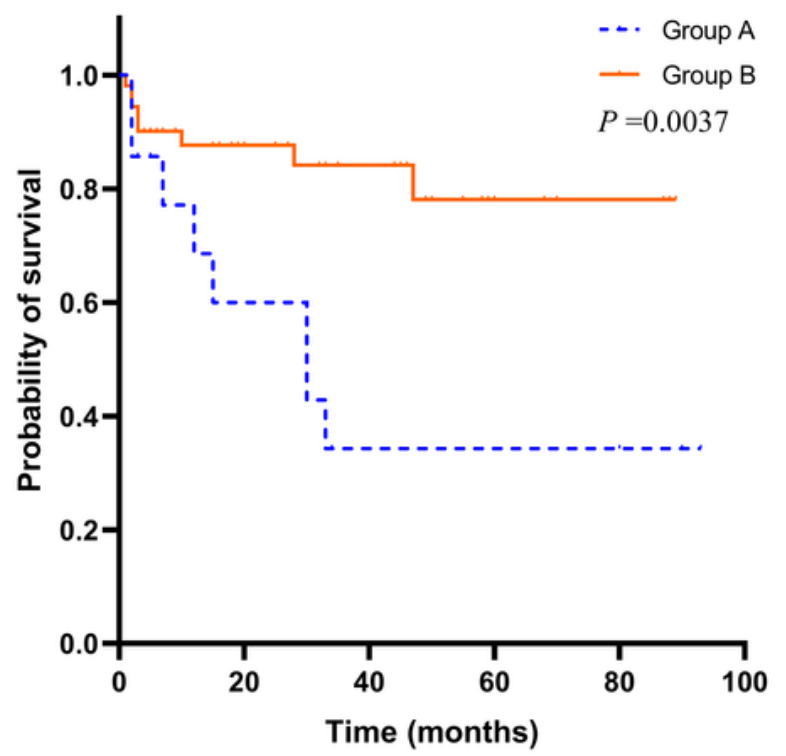

a

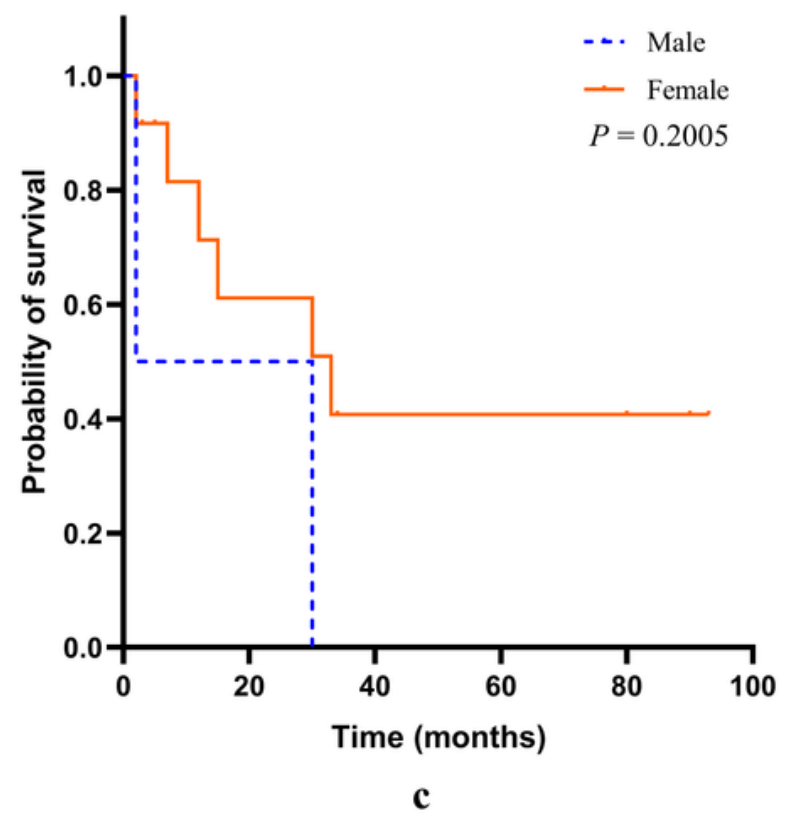

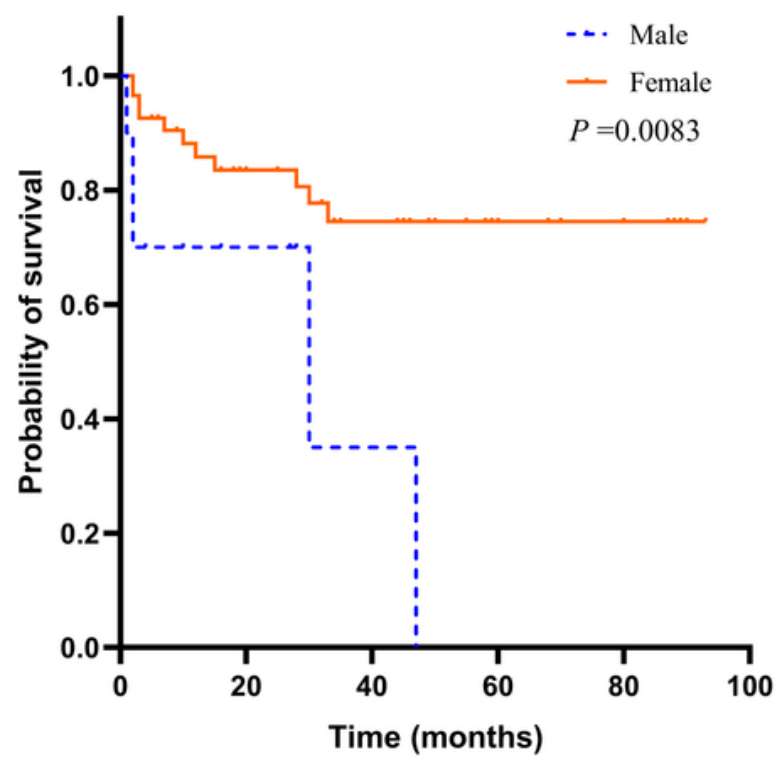

b

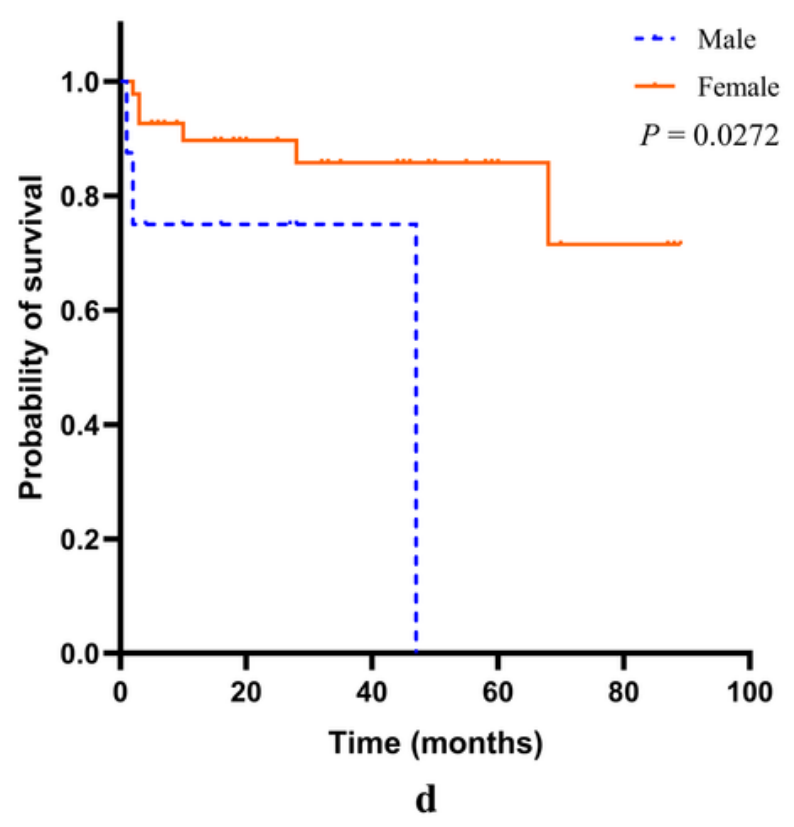

Figure 2

Kaplan Meier curves for survival

\section{Supplementary Files}

This is a list of supplementary files associated with this preprint. Click to download. 
- Additionalfile1.docx

Page 21/21 